\title{
Genetic parameters for predicted methane production and potential for reducing enteric emissions through genomic selection
}

\author{
Y. de Haas, ${ }^{* 1}$ J. J. Windig, ${ }^{*}$ M. P. L. Calus, ${ }^{*}$ J. Dijkstra,ł M. de Haan,§ A. Bannink,† and R. F. Veerkamp* \\ *Animal Breeding and Genomics Centre, Wageningen UR Livestock Research, PO Box 65, NL-8200 AB Lelystad, the Netherlands \\ †Animal Nutrition, Wageningen UR Livestock Research, PO Box 65, NL-8200 AB Lelystad, the Netherlands \\ $\ddagger$ Animal Nutrition Group, Wageningen Institute of Animal Sciences, Wageningen University, PO Box 338, NL-6700 AH Wageningen, \\ the Netherlands \\ §Systems Group, Wageningen UR Livestock Research, PO Box 65, NL-8200 AB Lelystad, the Netherlands
}

\section{ABSTRACT}

Mitigation of enteric methane $\left(\mathrm{CH}_{4}\right)$ emission in ruminants has become an important area of research because accumulation of $\mathrm{CH}_{4}$ is linked to global warming. Nutritional and microbial opportunities to reduce $\mathrm{CH}_{4}$ emissions have been extensively researched, but little is known about using natural variation to breed animals with lower $\mathrm{CH}_{4}$ yield. Measuring $\mathrm{CH}_{4}$ emission rates directly from animals is difficult and hinders direct selection on reduced $\mathrm{CH}_{4}$ emission. However, improvements can be made through selection on associated traits (e.g., residual feed intake, RFI) or through selection on $\mathrm{CH}_{4}$ predicted from feed intake and diet composition. The objective was to establish phenotypic and genetic variation in predicted $\mathrm{CH}_{4}$ output, and to determine the potential of genetics to reduce methane emissions in dairy cattle. Experimental data were used and records on daily feed intake, weekly body weights, and weekly milk production were available from 548 heifers. Residual feed intake $(\mathrm{MJ} / \mathrm{d})$ is the difference between net energy intake and calculated net energy requirements for maintenance as a function of body weight and for fat- and protein-corrected milk production. Predicted methane emission (PME; g/d) is 6\% of gross energy intake (Intergovernmental Panel on Climate Change methodology) corrected for energy content of methane $(55.65 \mathrm{~kJ} / \mathrm{g})$. The estimated heritabilities for PME and RFI were 0.35 and 0.40 , respectively. The positive genetic correlation between RFI and PME indicated that cows with lower RFI have lower PME (estimates ranging from 0.18 to 0.84 ). Hence, it is possible to decrease the methane production of a cow by selecting more-efficient cows, and the genetic variation suggests that reductions in the order of 11 to $26 \%$ in $10 \mathrm{yr}$ are theoretically possible, and could be even higher in a

Received April 12, 2011.

Accepted August 22, 2011.

${ }^{1}$ Corresponding author: Yvette.deHaas@wur.nl genomic selection program. However, several uncertainties are discussed; for example, the lack of true methane measurements (and the key assumption that methane produced per unit feed is not affected by RFI level), as well as the limitations of predicting the biological consequences of selection. To overcome these limitations, an international effort is required to bring together data on feed intake and methane emissions of dairy cows.

Key words: methane emission, feed efficiency, breeding, genomic selection

\section{INTRODUCTION}

Mitigation of enteric methane $\left(\mathrm{CH}_{4}\right)$ emission in ruminants has become an important area of research because enrichment of the atmosphere with $\mathrm{CH}_{4}$, as one of the most important non- $\mathrm{CO}_{2}$ greenhouse gases, is strongly linked to global warming. In cattle, enteric $\mathrm{CH}_{4}$, a colorless, odorless gas, is produced predominantly in the rumen (87\%) and to a small extent (13\%) in the large intestines (Murray et al., 1976). Rumen $\mathrm{CH}_{4}$ is primarily emitted from the animal by eructation. The conversion of feed material to $\mathrm{CH}_{4}$ in the rumen involves the integrated activities of various microbial species, with the final step carried out by methanogenic archaea (McAllister et al., 1996; Moss et al., 2000).

Opportunities for nutritional and microbial manipulation to reduce enteric $\mathrm{CH}_{4}$ emissions from livestock have been extensively researched and reviewed by several groups (e.g., Beauchemin et al., 2008; McAllister and Newbold, 2008). An additional mitigation measure that is inexpensive and provides a long-term effect would be the use of natural variation to breed for animals with lower $\mathrm{CH}_{4}$ yield ( $\mathrm{g}$ of $\mathrm{CH}_{4} / \mathrm{kg}$ of DMI; Cavanagh et al., 2008; Vlaming et al., 2008). Recent forums have begun to address the potential effect of animal genetics on emission intensity at the individual animal and whole-farm levels (Chagunda et al., 2009a; Wall et al., 2010). Genetic improvement of livestock is a particularly cost-effective technology, producing permanent and cumulative changes in performance. 
However, little information is available on opportunities to mitigate enteric $\mathrm{CH}_{4}$ via animal genetics.

Variation in enteric $\mathrm{CH}_{4}$ emission has been reported between animals, between breeds, and across time (Herd et al., 2002), providing potential for improvement through genetic selection. Unfortunately, measuring $\mathrm{CH}_{4}$ production directly from animals under practical conditions is currently difficult and hampers direct selection on reduced enteric $\mathrm{CH}_{4}$ in practice. Development of new direct or indirect measurement techniques will help enhance the capability for reducing emissions through genetic selection (for a review, see Wall et al., 2010). In the meantime, improvements can be made through selection on traits that are proxies for $\mathrm{CH}_{4}$ emissions. Such proxies include, for example, residual feed intake (RFI) (Hegarty et al., 2007) or predicted methane output using the Intergovernmental Panel on Climate Change (IPCC) Tier 2 methodology (IPCC, 2000). Use of IPCC Tier 2 methodology requires information such as feed intake measurements, diet composition, and animal weights to predict methane output. These data are expensive to record on a large number of animals, but substantially cheaper than measuring methane output in respiration chambers. The costs of recording make selection for this trait in a progeny testing program too difficult. However, with genomic selection (Meuwissen et al., 2001), this might become feasible, for example, by recording feed intake on 5,000 cows in a reference population to develop the genomic key for selection (Verbyla et al., 2010).

To evaluate the options for a breeding program to reduce methane emissions, insight into the genetic and phenotypic (co)variation across a lactation is required. In addition, the accuracy of genomic prediction in a small data set is important. Therefore, in this study, the objective is to establish whether first-lactation cows differed phenotypically, genetically, and genotypically in their individual predicted enteric $\mathrm{CH}_{4}$ emissions, and to determine the potential for genetic selection to reduce methane emissions in dairy cattle.

\section{MATERIALS AND METHODS}

\section{Data}

Data were collected on 665 Holstein-Friesian heifers born between 1990 and 1997 on an experimental farm ('t Gen, the Netherlands), of which 488 cows participated in the breeding program of CRV (Arnhem, the Netherlands). Comprehensive details on the data used can be found in Veerkamp et al. (2000) and Verbyla et al. (2010). All animals were housed together on a single farm under the same environmental and management conditions; all cows were fed ad libitum. Nutritive values were based on the Dutch feed evaluation system (Van Es, 1978) and on analyses of twice-weekly samples of the components of the ration. On average, the TMR (64\% DM) contained 6.87 MJ of net energy and $98 \mathrm{~g}$ of digestible $\mathrm{CP} / \mathrm{kg}$ of DM. The diet TMR consisted of dried grass, corn silage, and concentrates, in a ratio of 20:48:32 on average.

Body weight, feed intake, and milk yield were measured over 27 wk of the lactation, on average, with the bulk of data collected between wk 2 and 29 of lactation. Milk samples were taken on a fixed day of the week for measurement of fat, protein, and lactose yields. Feed intake was recorded daily using automated feed intake units. Body weight was recorded once a week. Recordings for milk, fat, and protein yields and feed intake deviating more than 3 standard deviations from the average in that lactation week were removed. Total number of complete weekly cow-records after editing was 17,759 .

Milk production was corrected for fat and protein content (FPCM, kg/d) and was calculated as $(0.337$ $+0.116 \times$ fat $\%+0.06 \times$ protein $\%) \times$ kilograms of milk. Residual feed intake (MJ/d) was calculated as the difference between net energy intake and the calculated net energy requirements for milk and maintenance costs as a function of BW, corresponding to previous calculations of energy balance by Veerkamp et al. (2000). Net energy in the milk (MJ) was calculated as 38.5 $\times$ kilograms of milk fat $+24.5 \times$ kilograms of milk protein $+16.5 \times$ kilograms of milk lactose (Veerkamp et al., 2000). Residual feed intake was calculated for each week separately, and therefore, loss or gain in BW was indirectly taken into account, because the weekly BW were included in the weekly calculations.

\section{Predicted Methane Emission}

Predicted methane emission (PME) was calculated for each animal as follows: PME $(\mathrm{g} / \mathrm{d})=$ feed intake $(\mathrm{kg}$ of $\mathrm{DM} / \mathrm{d}) \times 18.4(\mathrm{MJ} / \mathrm{kg}$ of $\mathrm{DM}) / 0.05565(\mathrm{MJ} / \mathrm{g})$ $\times 0.06 \times\{1+[2.38-$ level of intake (multiples of maintenance level)] $\times 0.04\}$ [Equation 1].

The standard value of energy released by each unit of feed DM was taken as 18.4 MJ/kg (Van Es, 1978), and the energy generated by methane was $0.05565 \mathrm{MJ} / \mathrm{g}$ (IPCC, 2006). A methane production level (in MJ/d) of $0.06 \times$ gross energy $(\mathbf{G E})$ intake $(\mathrm{MJ} / \mathrm{d})$ is recommended by IPCC (2000) for dairy cattle in Western Europe. According to Van Es (1978), and as applied in the Dutch feed evaluation system, each additional level of feed intake (in multiples of maintenance intake level) is associated with a $3 \%$ reduction in feed digestibility, which is also expected to reduce $\mathrm{CH}_{4}$ production per unit of feed. In the Dutch feed evaluation system, 
energy requirements are scaled to an average cow at feed intake level of $2.38 \times$ maintenance feed intake level. Higher feed intake levels generally decrease rumen $\mathrm{pH}$, and VFA production is then shifted toward propionic acid production at the expense of acetic acid and butyric acid production (Bannink et al., 2008), resulting in lower enteric methane production per kilogram of feed. Thus, a correction factor of 0.04 per unit feed intake level was assumed. This feed intake level correction factor results in reduced methane production estimates due to increased feed intake, in line with those estimated using a mechanistic model of rumen and hindgut fermentation (Bannink et al., 2011).

Initially, the weekly feed intake records were linked to the actual recorded diet composition (dried grass, corn silage, and concentrate) and an alternative prediction equation was used: PME $(\mathrm{g} / \mathrm{d})=$ [grass or grass silage $(\mathrm{kg}$ of $\mathrm{DM} / \mathrm{d}) \times 21.0(\mathrm{~g} / \mathrm{kg}$ of $\mathrm{DM})+$ concentrates $(\mathrm{kg}$ of $\mathrm{DM} / \mathrm{d}) \times 21.0(\mathrm{~g} / \mathrm{kg}$ of $\mathrm{DM})+$ corn silage $(\mathrm{kg}$ of $\mathrm{DM} / \mathrm{d}) \times 16.8(\mathrm{~g} / \mathrm{kg}$ of $\mathrm{DM})] \times\{1+[2.38-$ level of intake (multiples of maintenance level $) \times 0.04]\}$ [Equation 2].

Equation [2] was based on results of Bannink et al. (2011), which used a mechanistic model of rumen and hindgut fermentation, in which an average Dutch dairy cow diet had a $\mathrm{CH}_{4}$ production of $20 \mathrm{~g} / \mathrm{kg}$ of DM, and, on average, corn silage has a $20 \%$ lower $\mathrm{CH}_{4}$ production per kilogram of feed DM than grass herbage or grass silage. However, diet composition remained constant across the years of the experiment and the correlation between the 2 measures was 0.99. Both measures of PME had a close to unity correlation with DMI as well. Therefore, only the PME using equation [1] was used in further analysis.

\section{Genotyping}

In total, blood was stored for 588 out of the 665 heifers, and heifers were genotyped using the Illumina 50K SNP panel $(54,001$ SNP in total; Illumina, San Diego, CA). The quality control criteria for selecting the final set of SNP were a call rate of $>90 \%$, a GenCall score $>0.2$, and a GenTrain score $>0.55$ (Illumina descriptive statistics relating to genotype quality), a minor allele frequency of $>2.5 \%$, and a lack of deviation from Hardy-Weinberg equilibrium, $\chi^{2}<600$ (Wiggans et al., 2009). Animals with more than 5\% missing SNP genotypes were removed. Additionally, checks for Mendelian inconsistencies were performed and animals causing inconsistencies were removed (for more details, see Verbyla et al., 2010). After all editing steps, 43,011 SNP and 548 animals were retained.

\section{Statistical Analyses}

Lactation curves were determined for all traits by plotting the average by week of lactation. Phenotypic correlations between traits were estimated using all observations and using observations grouped in periods of $5 \mathrm{wk}$ (12 wk for 31-42 wk after lactation).

To determine whether the heritability of the traits changes over the lactation period and to what extent traits were genetically the same in different periods of the lactation, genetic parameters were determined using a random regression sire-maternal grandsire model:

$$
\begin{aligned}
Y_{k l m n} & =\mu+F I X E D+\left(\sum_{i=0}^{2} s_{i k} w k_{l}+\frac{1}{2} \times \sum_{i=0}^{2} s_{i m} w k_{l}\right) \\
& +\sum_{i=0}^{2} p e_{i n} w k_{l}+\varepsilon_{k l m n},
\end{aligned}
$$

where $Y_{k l m n}$ is the performance of animal $n$, with sire $k$ and maternal grand sire $m$, in week $l ; \mu$ is the average performance over all animals; FIXED includes year-season subclasses and a ninth-order polynomial regressions on week of lactation; and $s_{i k}$ and $s_{i m}$ are the ith order coefficients for the random regression polynomial on the week of lactation $w k_{l}$ of sire $k$ and maternal grandsire $m$. Here, a second-order polynomial was fitted so the coefficients included an intercept $(i=0)$, slope $(i=1)$, and quadratic term $(i=2)$. One variance component was fitted by overlaying the relationship matrix for sire and maternal grandsire, $p e_{i n}$ is the $i$ th order coefficient for the polynomial for the permanent environmental effect of animal $n$ on week of lactation $w k_{l}$, and $\varepsilon_{k l m n}$ is the residual effect.

The random regressions were restricted to a secondorder polynomial because of convergence problems for higher order polynomials. This definition of the genetic model resulted in estimated sire variances of the polynomial coefficients and covariances between these coefficients.

Residual variances were estimated for periods of 5 wk. Additive genetic variances, heritabilities, and genetic correlations were calculated from the covariance functions for the average week (e.g., wk 2.5, 7.5) of each 5-wk period. Heritabilities were calculated as 4 times the sire variance divided by the sum of 1.25 $\times$ sire variance $[1.25$ because both the sire variance and the maternal grandsire variance (i.e., $0.25 \times$ sire variance) were estimated in the model], the permanent environmental variance, and the residual variance of the corresponding 5 -wk period.

The same random regression model was used in a bivariate analysis to obtain genetic correlations of PME 
and of PME per kilogram of FPCM with other traits. Genetic correlations were calculated from the covariance function for the midpoint of 5 -wk periods. The 6 $\times 6$ matrix with estimated covariance components $(\mathbf{V})$ for the intercept, slope and quadratic term for each trait was used to obtain genetic correlations between the 2 traits in 5 -wk periods, the variance-covariance matrix was computed as MVM', where

$$
\begin{gathered}
\mathbf{M}=\begin{array}{cc}
\mathbf{M}_{\mathbf{\Phi}} & \mathbf{0} \\
\mathbf{0} & \mathbf{M}_{\boldsymbol{\Phi}}
\end{array} \\
\text { with } \mathbf{M}_{\boldsymbol{\Phi}}=\left[\begin{array}{ccc}
\Phi_{0}\left(w k_{\text {period } 1}\right) & \Phi_{1}\left(w k_{\text {period } 1}\right) & \Phi_{2}\left(w k_{\text {period } 1}\right) \\
\Phi_{0}\left(w k_{\text {period } 2}\right) & \Phi_{1}\left(w k_{\text {period } 2}\right) & \Phi_{2}\left(w k_{\text {period } 2}\right) \\
\vdots & \vdots & \vdots \\
\Phi_{0}\left(w k_{\text {period } 5}\right) & \Phi_{1}\left(w k_{\text {period } 5}\right) & \Phi_{2}\left(w k_{\text {period } 5}\right)
\end{array}\right] \text {, }
\end{gathered}
$$

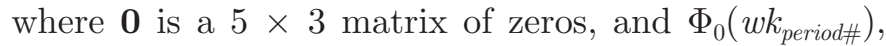
$\Phi_{1}\left(w k_{\text {period\# }}\right)$, and $\Phi_{2}\left(w k_{\text {period\# }}\right)$ are the design values of the second-order orthogonal Legendre polynomial for the 5 -wk periods of lactations.

\section{Analysis of Genomic Selection}

Effects of SNP were estimated using Bayesian stochastic search variable selection (SSVS; George and McCulloch, 1993). This model samples an indicator variable $I_{j}$ that determines whether $\mathrm{SNP}_{j}$ has a large effect or whether the effect is small and therefore scaled back toward zero. The prior QTL probability $p$ reflects the expected number of QTL that affect the trait of interest. Here, we assumed that 100 QTL affect PME, and therefore $p$ was $\sim 0.002$. The applied SNP model was

$$
\mathbf{y}=1_{n} \mu+\sum_{j=1}^{m}\left[\mathbf{X}_{j}\left(\mathbf{q}_{j} v_{j}\right)\right]+\mathbf{Z u}+\mathbf{e},
$$

where $\mathbf{y}$ is the vector of $n$ preadjusted $\mathrm{CH}_{4}$ phenotypes; $\mu$ is the mean; $m$ is the number of SNP markers; $\mathbf{X}_{j}$ is the $(n \times k)$ design matrix containing the information on the possible $k$ alleles at the $j$ th marker for all individuals (where $x_{j k}=0,1,2$, having 0,1 , or 2 copies of the $k$ th allele, respectively); $\mathbf{q}_{j}$ is the vector $(k \times 1)$ containing the effects of all $k$ possible alleles at locus $j$, where $q_{j k}$ are drawn from a standard normal distribution $N(0,1) ; v_{j}$ is the standard deviation of the allelic effects at locus $j$ and is dependent on whether the locus effect is considered significant using the indicator variable; $\mathbf{u}$ is the vector of random additive polygenic ef- fects of length $n$ ( $\mathbf{Z}$ is the associated design matrix) and is assumed to be normally distributed, $\mathbf{u} \sim N\left(0, \mathbf{A} \sigma_{u}^{2}\right)$, where $\mathbf{A}$ is the pedigree-derived additive genetic relationship matrix; and $\mathbf{e}$ is the residual error also assumed to be normally distributed, e $\sim N\left(0, \mathbf{I} \sigma_{e}^{2}\right)$, where $\mathbf{I}$ is the $n \times n$ identity matrix. For the full specification of the priors used and an alternative formulation of the model, see Meuwissen and Goddard (2004) and Calus et al. (2008).

Phenotypes for the SNP analysis were calculated as the total PME for wk 1 to 30. Individual PME curves were predicted using a slightly different model than used for the estimation of heritabilities across and genetic correlations between test days. This adjusted model was

$$
Y_{i j}=\mu+F I X E D+\sum_{k=0}^{5} \delta_{k} \times w k_{j}+\varepsilon_{i j k},
$$

where $Y_{i j}$ is the performance of animal $i$ in week $j ; \mu$ is the average performance over all animals; FIXED includes year-season subclasses, subclasses for age at calving, and a ninth-order polynomial regression on week of lactation; $\delta_{k}$ are the coefficients for the fifthorder random regression on the week of lactation of animal $i$; and $\varepsilon_{i j k}$ is the residual effect.

The PREDICT statement in ASReml (Gilmour et al., 2006) was used to predict weekly PME, preadjusted for year-season and age at calving. Phenotypes for the SNP model were obtained by summing the predictions across wk 1 to 30 . Estimated SNP effects obtained from the above model were used for 2 purposes. First, SNP effects were analyzed to determine if any major QTL for PME could be mapped using the present data set. For this purpose, all available records were analyzed in 4 different Gibbs chains of 100,000 cycles, discarding 10,000 as burn-in. Following the advice of Gelman and Rubin (1992), 4 Gibbs chains with different starting points were run for each of the applied models to verify that posterior estimates were not dependent on the starting points of the Gibbs chain. Posterior means were calculated as averages across all cycles after the burn-in. Presented results are the average of the posterior means across the 4 Gibbs chains. Second, estimated SNP effects were used to assess the accuracy of prediction based on SNP information. For this purpose, a 10-fold cross-validation was performed. Each animal had its phenotype omitted randomly once in 1 of the 10 cross-validation steps. Predicted direct genomic values (DGV) for animals with omitted phenotypes were related to their phenotypes to obtain the accuracy of predicting the phenotypes $\left(r_{y \hat{g}}\right)$. This was translated 
into an accuracy of the DGV $\left(r_{g \hat{g}}\right)$ by dividing by the square root of the heritability. In each of the cross-validation steps, 1 Gibbs chain of 50,000 cycles was run, discarding 10,000 as burn-in. Animals whose DGV were predicted might have had (close) relatives in the remaining reference population, leading to an increased value for the obtained accuracy. To evaluate the effect of relationships alone on the realized accuracies, we also performed the cross-validation for a model that used only pedigree information.

\section{RESULTS}

\section{Descriptive Analysis}

Yield of FPCM followed the standard lactation curve with a steep increase in the first week of lactation, reaching peak levels of about $30 \mathrm{~kg} / \mathrm{d}$ in wk 9 to 10 and subsequently decreasing gradually to about $20 \mathrm{~kg} / \mathrm{d}$ at the end of lactation (Figure 1a). Predicted methane emission increased more gradually, reached its maximum of around $400 \mathrm{~g} / \mathrm{d}$ around mid lactation, and remained at that level until the end of lactation, showing a similar shape as a standard feed intake curve. When PME was expressed as grams per kilograms of FPCM, it increased throughout the lactation from 10 $\mathrm{g} / \mathrm{kg}$ at the start to $15 \mathrm{~g} / \mathrm{kg}$ at the end of the lactation (Figure 1b).

When taken across the test-day records of all animals, PME and FPCM were not strongly related (Table 1). Variation was found in PME per kilogram of FPCM, not only between weeks of lactation but also between animals. The overall phenotypic correlation between PME and FPCM was 0.26, and PME had a close to unity correlation with DMI, which was a direct consequence of the use of equation [1] to calculate PME and the lack of variation in dietary composition. The phenotypic correlation between RFI and DMI or with PME was 0.72 (Table 1). Across the lactation, the correlation between PME and FPCM increased from 0.19 at the start of the lactation to 0.58 at the end of the lactation (Table 2). This suggests that cows with a higher milk yield have a higher DMI and consequently higher PME, especially toward the end of the lactation. The correlation between PME and RFI remained between 0.51 and 0.66 throughout the lactation (Table 2).

\section{Genetic Analysis}

Over the whole period, some variation was observed in the heritabilities for PME, FPCM, RFI, and PME per kilogram of FPCM (Table 3), all being between 0.35 and 0.58 . Across the lactation, the lowest heritability
(0.29) was found in the first lactation period for PME and in the second-to-last lactation period for RFI. The estimated heritabilities for FPCM and RFI stabilized about half way in the lactation (0.35 and 0.30$)$.

The genetic correlation of enteric $\mathrm{CH}_{4}$ emission per day between the first and last lactation periods was low (0.36, Table 4), and for PME per kilogram of FPCM, this correlation was higher: 0.53 , respectively (Table 5). The genetic correlation between PME and FPCM changed from negative at the start of the lactation to positive in the last period (Table 6). The genetic correlation between PME and RFI and between PME per kilogram of FPCM and RFI remained positive throughout the whole lactation. The correlations between FPCM and RFI and between PME per kilogram of FPCM and FPCM remained negative (Table 6).

\section{SNP Effects}

The posterior QTL probabilities were small in general $(<0.07$; Figure 2), but 7 SNP on 5 chromosomes (13, $18,24,26$, and 27) had a Bayes factor $>10.1$ (Figure 2). The maximum posterior probability was 0.066 for SNP BTA-43186-no-rs located on BTA 18 (rs41581216); the next highest posterior probability was 0.036 for SNP ARS-BFGL-NGS-27628 (rs43088681) located on BTA 13. The SNP with the next highest posterior probability were on BTA 27 (ARS-BFGL-NGS-14626, rs108950322; and Hapmap50424-BTA-63130, rs110518457) and BTA 24 (Hapmap48814-BTA-57491, rs41644372). On BTA 26, 2 closely linked SNP (BFGL-NGS-113660, rs109138979; and BFGL-NGS-115245, rs42084082) had a Bayes factor $>10.1$. In this area, the effect was spread across many surrounding, closely linked SNP, indicating a clear signal in this region. Despite the clear signal of some of the SNP and the consistency of results across multiple chains of the Gibbs sampler, the estimated variance explained by the SNP with the largest effect was only $0.2 \%$ of the total genetic variance.

The DGV of all animals were predicted once, when omitting their phenotypes, using cross-validation. Accuracy of predicting the phenotype was almost twice as high using SNP information (DGV) compared with using pedigree information (EBV; $r_{y \hat{g}}$; Table 7$)$. This difference was somewhat smaller for the accuracies of the predicted breeding values $\left(r_{g \hat{g}}\right.$; Table 7$)$. Differences on the reliability scale were almost 3 times as large for DGV compared with EBV, implying that 3 times as much variation was explained by the SNP compared with the pedigree, and therefore, that the accuracy of prediction using the estimated SNP effects was only partly driven by relationships between evaluated and reference animals. 


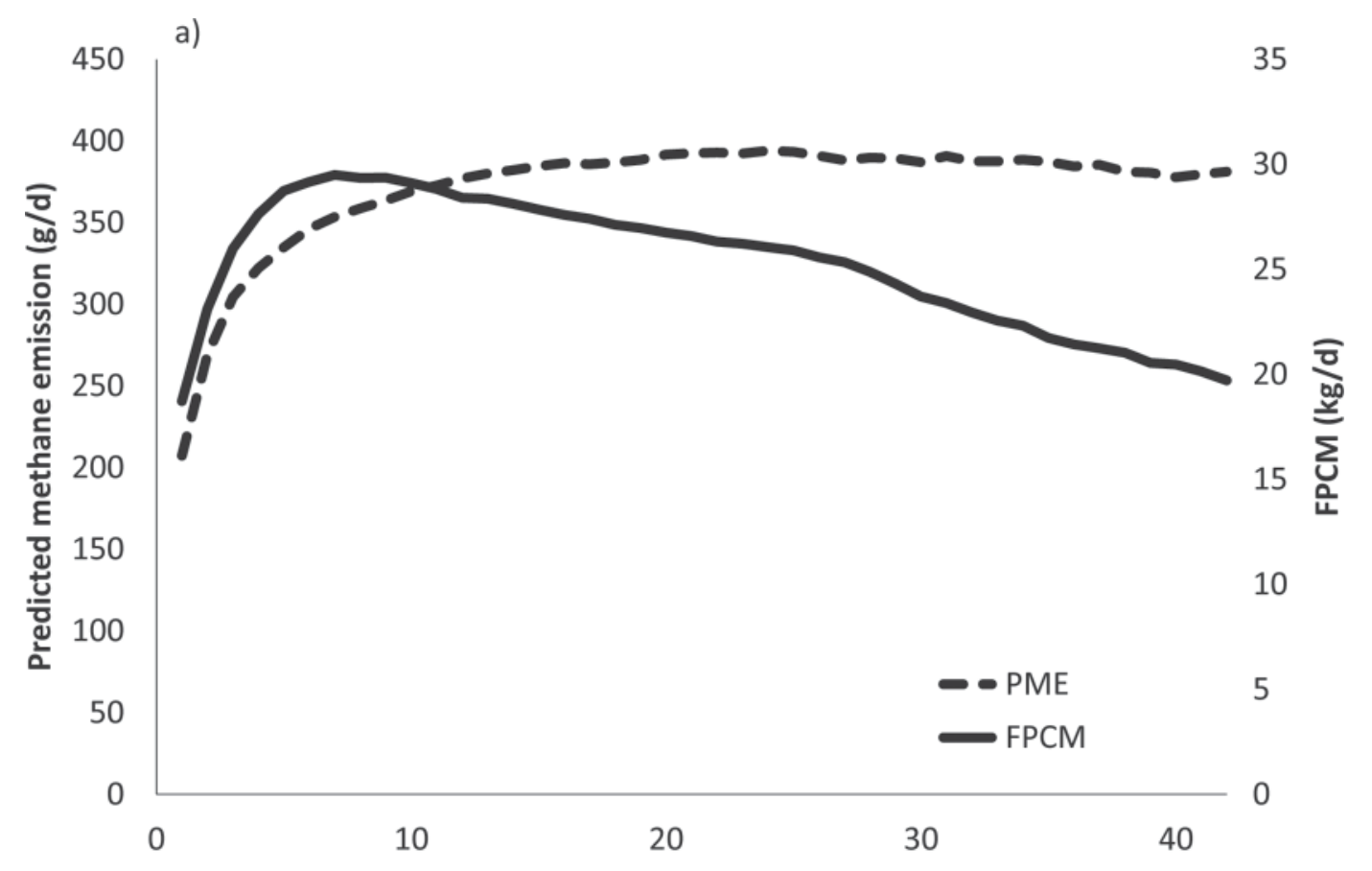

b)

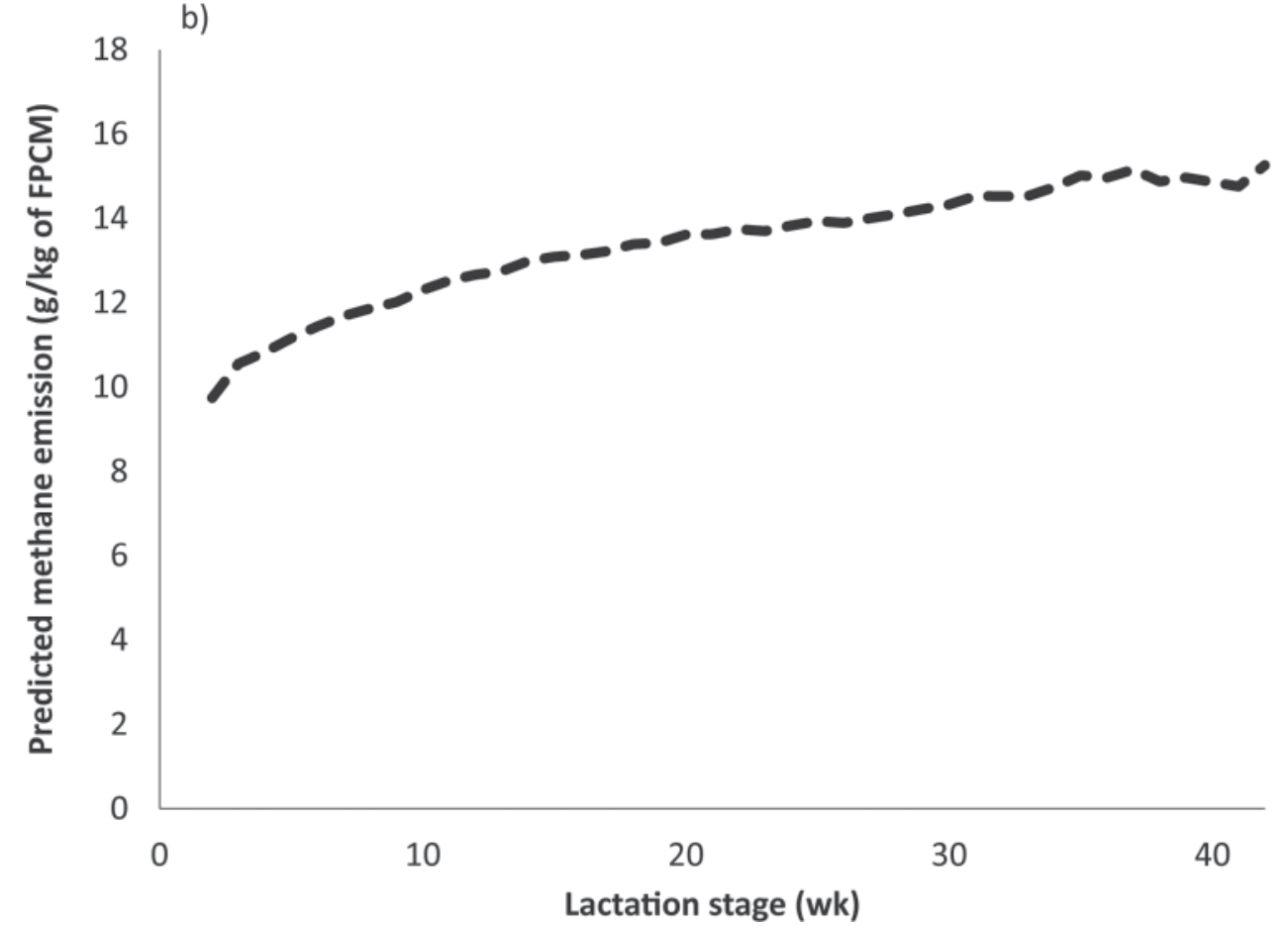

Figure 1. The lactation curves for (a) fat- and protein-corrected milk production (FPCM; $\mathrm{kg} / \mathrm{d}$ ) and predicted enteric methane emission (PME) in grams per day and (b) PME in grams per kilogram of FPCM up to 42 wk in lactation.

\section{DISCUSSION}

The objective of this study was to evaluate the phenotypic variance of PME in dairy heifers, to evaluate how it is associated with milk yield and RFI, and to determine its genetic basis. This information is essential for the incorporation of enteric $\mathrm{CH}_{4}$ emission in selection programs. Enteric $\mathrm{CH}_{4}$ emission of dairy cows is rarely recorded and consequently, no phenotypic records were available. For selection in practice, improvements could also be made through selection on traits that are proxies for enteric $\mathrm{CH}_{4}$ emission. In short, Wall et al. (2010) 
Table 1. Phenotypic correlations between predicted enteric methane emission (PME), fat- and protein-corrected milk production (FPCM), $\mathrm{DMI}$, and residual feed intake (RFI) in full lactations

\begin{tabular}{lcrc}
\hline Item & $\begin{array}{l}\text { PME } \\
(\mathrm{g} / \mathrm{d})\end{array}$ & $\begin{array}{c}\text { FPCM } \\
(\mathrm{kg} / \mathrm{d})\end{array}$ & $\begin{array}{c}\text { DMI } \\
(\mathrm{kg} / \mathrm{d})\end{array}$ \\
\hline FPCM $(\mathrm{kg} / \mathrm{d})$ & 0.26 & & \\
DMI $(\mathrm{kg} / \mathrm{d})$ & 0.99 & 0.31 & 0.72 \\
RFI $(\mathrm{MJ} / \mathrm{d})$ & 0.72 & -0.45 & 0 \\
\hline
\end{tabular}

reviewed 3 routes through which genetic improvement can help to reduce emissions per kilogram of product: (1) improving productivity and efficiency, (2) reducing wastage in the farming system, and (3) directly selecting on emissions, if or when these are measurable. The current study focused on the first and third paths, and RFI (Hegarty et al., 2007; Bell et al., 2011), PME (according to the IPCC methodology, IPCC, 2000), and FPCM were investigated as proxy traits for methane. Selection on proxies can be as effective as selection on the direct trait, especially when genetic correlations are relatively strong and more records for the proxy are available or recording of the proxy is more accurate with a higher heritability (see Wall et al., 2010). To establish the accuracy of predictions using proxies, we still need sufficient records of enteric $\mathrm{CH}_{4}$ emission on individual cows, which are not yet available, which was a handicap for the current study. In the present study, PME was used as a proxy trait; its variation is mainly determined by the variation in feed intake of cows, because PME is calculated directly from feed intake. A similar discussion applies to studies that use RFI to select for improved feed efficiency (Veerkamp and Emmans, 1995), with the same risk of selecting for spurious variation in, for example, behavior of animals or energy mobilization (Veerkamp, 2002). Still, it is important to establish the variation in traits such as RFI and PME, and to establish the importance of their genetic background, as this might be the first step toward more detailed recording in practice.

In the present study, methane emission was predicted based on the IPCC Tier 2 method. The IPCC Tier 2 estimation may provide an accurate estimate of $\mathrm{CH}_{4}$ emissions across diets when evaluated against actual $\mathrm{CH}_{4}$ observations, but the method is not suitable for predicting changes in $\mathrm{CH}_{4}$ emissions among diets used in mitigation studies (Ellis et al., 2010). However, diet composition was relatively constant in the present study. Furthermore, methane emission per unit feed GE was assumed constant and independent of variation between animals in feed fermentability in rumen and hindgut. It is intrinsically difficult to investigate differences in net efficiency (such as fermentation or digestion) at the genetic level, because detailed and expensive recording
Table 2. The number of weekly observations (N) per period and the phenotypic correlations between predicted methane emission (PME; $\mathrm{g} / \mathrm{d}$ ) and fat- and protein-corrected milk production (FPCM; kg/d), and between PME and residual feed intake (RFI; MJ/d) within periods of the lactation

\begin{tabular}{lccc}
\hline $\begin{array}{l}\text { Period } \\
(\text { wk })\end{array}$ & $\mathrm{N}$ & PME - FPCM & PME - RFI \\
\hline $1-5$ & 3,009 & 0.19 & 0.66 \\
$6-10$ & 3,155 & 0.31 & 0.56 \\
$11-15$ & 3,108 & 0.49 & 0.52 \\
$16-20$ & 2,933 & 0.56 & 0.51 \\
$21-25$ & 2,720 & 0.60 & 0.49 \\
$26-30$ & 1,918 & 0.57 & 0.62 \\
$31-42$ & 2,036 & 0.58 & 0.56 \\
\hline
\end{tabular}

is required on a large scale (Veerkamp and Emmans, 1995). However, more-efficient animals appear to have a higher rate of fermentation or digestion and have a different profile of VFA, which may affect $\mathrm{CH}_{4}$ production. For example, Nkrumah et al. (2006) observed that steers with a low RFI had a higher digestibility $(P<0.10)$ than steers with a high RFI, which is likely associated with increased fermentability of nutrients and consequently increased methane production per unit feed. Hegarty et al. (2007) observed a numerically larger methane production per kilogram of DMI for low versus high RFI steers (16.3 and $14.7 \mathrm{~g} / \mathrm{kg}$ of DM, respectively). Guan et al. (2008) reported an almost doubled $(P=0.059)$ total VFA concentration in rumen fluid of low compared with high RFI steers, indicating more active microbial fermentation and relatively higher methane production in low RFI steers. Thus, the limited evidence available suggests that improved feed efficiency is partly or fully related to a greater extent of fermentation and digestion of ingested feed, and consequently to a higher amount of methane per unit feed. In other words, compared with $\mathrm{CH}_{4}$ production being $6 \%$ of GE intake on average, efficient animals may have a higher fraction, and inefficient animals a lower fraction, of GE directed toward methane.

\section{Variation in PME Within Lactation Among Cows}

The estimated phenotypic variances showed that large variation in PME exists among cows. Predicted enteric $\mathrm{CH}_{4}$ emission varied between 200 and 400 $\mathrm{g} / \mathrm{d}$, both among low-producing cows (e.g., $15 \mathrm{~kg}$ of FPCM/d) and among high-producing cows (e.g., $45 \mathrm{~kg}$ of $\mathrm{FPCM} / \mathrm{d}$ ). For a whole lactation, this equates to some cows producing around $60 \mathrm{~kg}$ more $\mathrm{CH}_{4}$ than other cows at the same FPCM production level. The low phenotypic correlation between PME and FPCM also indicates that high-producing cows are not producing less methane per se. The phenotypic correlations also show that the high-producing cows have higher DMI 
Table 3. Estimated heritabilities ${ }^{1}$ for predicted methane emission (PME; g/d), fat- and protein-corrected milk production (FPCM; kg/d), residual feed intake (RFI; MJ/d), and PME per FPCM for the whole lactation period monitored within 5 -wk lactation periods

\begin{tabular}{lcccc}
\hline $\begin{array}{l}\text { Lactation } \\
\text { period (wk) }\end{array}$ & PME & FPCM & RFI & PME/FPCM \\
\hline $0-42$ & 0.35 & 0.38 & 0.40 & 0.58 \\
$1-5$ & 0.29 & 0.48 & 0.84 & 0.66 \\
$6-10$ & 0.30 & 0.43 & 0.70 & 0.65 \\
$11-15$ & 0.36 & 0.38 & 0.46 & 0.46 \\
$16-20$ & 0.40 & 0.35 & 0.31 & 0.39 \\
$21-25$ & 0.42 & 0.36 & 0.29 & 0.44 \\
$26-30$ & 0.35 & 0.36 & 0.30 & 0.55 \\
\hline
\end{tabular}

${ }^{1}$ The standard error of the estimated heritability was 0.12 for PME, 0.14 for FPCM, 0.11 for RFI, and 0.15 for PME/FPCM for the full lactation $(0-42 \mathrm{wk})$. The standard errors ranged between 0.10 and 0.12 for PME, between 0.12 and 0.14 for FPCM, between 0.10 and 0.13 for RFI, and between 0.12 and 0.15 for PME/FPCM for the heritabilities estimated in the different lactation periods.

and lower RFI (i.e., are more efficient). This is also shown by the positive phenotypic correlation between PME and RFI, indicating that cows with a low RFI (i.e., an apparently efficient cow) also have a low PME.

In the present analyses, diet composition remained constant across the years of the experiment. In practice, however, diet composition of dairy cattle can vary widely, related to (1) genetic potential for milk production, (2) days in milk, and (3) availability of local feed resources. Consistent ranking of lowly versus highly efficient animals in various dietary situations that occur in practice would be desirable. Little is known about the effect of diet composition on consistency of feed efficiency of individual animals. In an extensive study with steers fed grower and finisher diets, Durunna et al. (2011) observed that switching diets affected the feed efficiency ranking of steers. The correlation between RFI of the grower and the finisher diet was 0.33 . Thus, further evaluation in different dietary or other management situations on the RFI estimates is required.

\section{Genetic Variation and Theoretical Gain in PME}

The genetic parameters show that a genetic basis exists for PME. With an estimated heritability of 0.35 for PME and 0.58 for PME per FPCM over the whole lactation, one-third of the natural variation among cows in PME and almost $60 \%$ of the natural variation among cows in PME per FPCM was explained by its genetic background, which gave a genetic standard deviation of about $6 \mathrm{~kg}$ of $\mathrm{CH}_{4}$ per lactation and $1.5 \mathrm{~g}$ of $\mathrm{CH}_{4}$ per $\mathrm{kg}$ of FPCM produced. The results in this study showed that several SNP proved to be associated with PME in this data set. However, the amount of variation explained in PME by those SNP was so low that it is unlikely that a few single genes could be used to select accurately for reduced PME. Whole-genome selection (Meuwissen et al., 2001), in which a SNP key is developed and continuously updated every year, appears a better avenue to follow for a breeding program. Reliabilities in this study were still too low for effective selection and lower than those found for energy balance (Verbyla et al., 2010).

Using the genetic standard deviations in PME, theoretical predictions could be made about the expected effect of genetic selection. When assuming a genetic progress of 0.22 genetic SD per year (e.g., as in a classical dairy cattle breeding program; Rendel and Robertson, 1950), it follows that the average PME can be reduced in $10 \mathrm{yr}$ with about $13 \mathrm{~kg} / \mathrm{cow}$ per lactation;

Table 4. Estimated genetic correlations (below diagonal) and permanent environmental correlations (above diagonal) for predicted methane emission (PME; $\mathrm{g} / \mathrm{d}$ ) between different 5 -wk periods of the lactation ${ }^{1}$

\begin{tabular}{lcccccc}
\hline $\begin{array}{l}\text { Period } \\
\text { (wk) }\end{array}$ & $1-5$ & $6-10$ & $11-15$ & $16-20$ & $21-25$ & $26-30$ \\
\hline $1-5$ & & 0.89 & 0.66 & 0.47 & 0.36 & 0.31 \\
$6-10$ & 0.82 & & 0.92 & 0.80 & 0.69 & 0.57 \\
$11-15$ & 0.51 & 0.91 & & 0.96 & 0.89 & 0.74 \\
$16-20$ & 0.34 & 0.80 & 0.98 & & 0.97 & 0.86 \\
$21-25$ & 0.31 & 0.75 & 0.93 & 0.98 & & 0.95 \\
$26-30$ & 0.36 & 0.70 & 0.84 & 0.89 & 0.96 & \\
\hline
\end{tabular}

${ }^{1}$ The standard errors ranged between 0.02 and 0.23 for the estimated genetic correlations and between 0.01 and 0.08 for the permanent environmental correlations, where the lactation periods close to each other had the strongest correlation and the lowest standard errors. 
Table 5. Estimated genetic correlations (below diagonal) and permanent environmental correlations (above diagonal) for predicted methane emission (PME; $\mathrm{g} / \mathrm{d}$ per $\mathrm{kg}$ of fat- and protein-corrected milk yield) between different 5 -wk periods of the lactation ${ }^{1}$

\begin{tabular}{lcccccc}
\hline $\begin{array}{l}\text { Period } \\
\text { (wk) }\end{array}$ & $1-5$ & $6-10$ & $11-15$ & $16-20$ & $21-25$ & $26-30$ \\
\hline $1-5$ & & 0.96 & 0.84 & 0.71 & 0.62 & 0.57 \\
$6-10$ & 0.98 & & 0.96 & 0.87 & 0.78 & 0.69 \\
$11-15$ & 0.91 & 0.97 & & 0.97 & 0.90 & 0.80 \\
$16-20$ & 0.75 & 0.85 & 0.95 & & 0.97 & 0.90 \\
$21-25$ & 0.60 & 0.70 & 0.85 & 0.97 & & 0.97 \\
$26-30$ & 0.53 & 0.62 & 0.76 & 0.90 & 0.98 & \\
\hline
\end{tabular}

${ }^{1}$ The standard errors ranged between 0.01 and 0.15 for the estimated genetic correlations and between 0.01 and 0.05 for the permanent environmental correlations, where the lactation periods close to each other had the strongest correlation and the lowest standard errors.

that is, from an average in the population of 120 to 107 $\mathrm{kg} / \mathrm{cow}$ per lactation, or from 13 to $9 \mathrm{~g} / \mathrm{kg}$ of FPCM. Thus, clear potential exists for genetic improvement of these 2 traits, with potential reductions of 11 and $26 \%$ in $10 \mathrm{yr}$ for PME and PME/FPCM, respectively. At first sight, this might seem an excessively large improvement. However, when ranking the cows in the current database on PME/FPCM, the 50 best cows produced $11.31 \mathrm{~g}$ of PME per $\mathrm{kg}$ of FPCM, and the 50 worst cows produced $16.20 \mathrm{~g}$ of PME per kg of FPCM. In other words, the worst cows produced $42 \%$ more PME per kilogram of FPCM than the best cows. An improvement up to $25 \%$ is therefore realistic.

\section{Achievability of Genetic Gains in Methane Reduction}

The small data set available gives limited accuracy of the genetic parameters, but other uncertainties and assumptions might also affect the true genetic gain that can be achieved. The most important factors will be discussed here: (1) the association with true enteric $\mathrm{CH}_{4}$ emissions, (2) correlated responses at the system level, (3) the effect of individual cow variation at system level, and (4) realistic breeding program.

True Methane Reduction. The predictions in this study were based on indicator traits (e.g., RFI or PME). However, the association between these indica- tor traits and true $\mathrm{CH}_{4}$ output is not yet known very accurately, which makes it intrinsically impossible to predict the effects of predictors on true $\mathrm{CH}_{4}$ output. Only a few studies had real methane records available (Nkrumah et al., 2006; Hegarty et al., 2007) and linked to RFI. A moderate favorable genetic correlation of 0.44 was estimated between $\mathrm{RFI}$ and true $\mathrm{CH}_{4}$ output (Nkrumah et al., 2006), indicating that cows that are genetically predisposed to have a lower RFI also have a lower true enteric $\mathrm{CH}_{4}$ output. That the estimated genetic correlation between RFI and true $\mathrm{CH}_{4}$ output was below unity was not surprising, because RFI contains only the feed intake after adjusting for production and not the full DMI, which is important for the true $\mathrm{CH}_{4}$ output. Selecting on a predictor trait will have a direct effect on the trait of interest as well. Predicting methane emission based on DMI and diet composition gives adequate results. Ellis et al. (2007) developed prediction equations of $\mathrm{CH}_{4}$ production on beef and dairy data using commonly measured dietary variables and validated the models with real $\mathrm{CH}_{4}$ output. They reported $\mathrm{R}^{2}$ up to $65 \%$ for equations based on energy content of the diet and DMI, indicating a reasonable association between the predicted and real $\mathrm{CH}_{4}$ output. By selecting on a reduced PME, the true enteric $\mathrm{CH}_{4}$ emission will be reduced as well. Therefore, until real enteric $\mathrm{CH}_{4}$ emission data are available on a large scale,

Table 6. Estimated genetic correlations between predicted methane emission (PME; $\mathrm{g} / \mathrm{d}$ ) and fat- and proteincorrected milk production (FPCM; kg/d), between PME and residual feed intake (RFI; MJ/d), between FPCM and RFI, between PME per FPCM (g/d per $\mathrm{kg}$ ) and FPCM, and between PME per FPCM and RFI within the whole lactation ( $0-42 \mathrm{wk})$ and in different periods of the lactation

\begin{tabular}{lccccc}
\hline $\begin{array}{l}\text { Period } \\
\text { (wk) }\end{array}$ & PME - FPCM & PME - RFI & FPCM - RFI & PME/FPCM - FPCM & PME/FPCM - RFI \\
\hline $0-42$ & 0.31 & 0.32 & -0.84 & -0.87 & 0.98 \\
$1-5$ & -0.66 & 0.84 & -0.98 & -0.95 & 1.00 \\
$6-10$ & -0.18 & 0.50 & -0.94 & -0.91 & 0.99 \\
$11-15$ & 0.42 & 0.18 & -0.78 & -0.86 & 0.94 \\
$16-20$ & 0.67 & 0.21 & -0.55 & -0.84 & 0.83 \\
$21-25$ & 0.70 & 0.34 & -0.43 & -0.85 & 0.76 \\
$26-30$ & 0.60 & 0.43 & -0.49 & -0.85 & 0.82 \\
\hline
\end{tabular}


Table 7. Accuracies and reliabilities ${ }^{1}$ of direct genomic values (DGV) and EBV for predicted enteric methane emission

\begin{tabular}{lcccc}
\hline Model & $r_{y \hat{g}}$ & $r_{g \hat{g}}$ & $r_{y \hat{g}}^{2}$ & $r_{g \hat{g}}^{2}$ \\
\hline DGV & 0.219 & 0.369 & 0.048 & 0.136 \\
EBV & 0.122 & 0.207 & 0.015 & 0.043 \\
\hline
\end{tabular}

$1 r_{y \hat{g}}=$ Pearson correlation between the predicted breeding values $(\hat{g})$ and the phenotypes $(y) ; r_{g \hat{q}}=$ accuracy of the predicted breeding values $(\hat{g})$ (correlation with the true breeding values, $g$ ); $r_{y \hat{g}}^{2}=$ reliability of the predicted phenotypes; and $r_{g \hat{g}}^{2}=$ reliability of the predicted breeding values.

selection on indicator traits can be of great help to reduce the environmental impact of dairy cattle.

Correlated Responses at the System Level. It is likely that simultaneous selection for higher yield and lower feed intake will increase the reliance on body energy reserves to support lactation (Veerkamp, 1998). The genetic correlations in this study suggest that selection for lower methane emission increases milk production in the beginning of the lactation and will decrease it toward the end of the lactation. The increased milk production in early lactation might further increase the negative energy balance cows usually experience and will increase health and fertility problems (de Vries and Veerkamp, 2000; Friggens and Newbold, 2007; van Knegsel et al., 2007). This will need more careful investigation to separate the genetic and nutritional effects of negative energy balance (Veerkamp et al., 2003; Friggens et al., 2007), because poorer health and fitness in the dairy herd might put a limit to the selection pressure on $\mathrm{CH}_{4}$ emission and may reduce the net effect

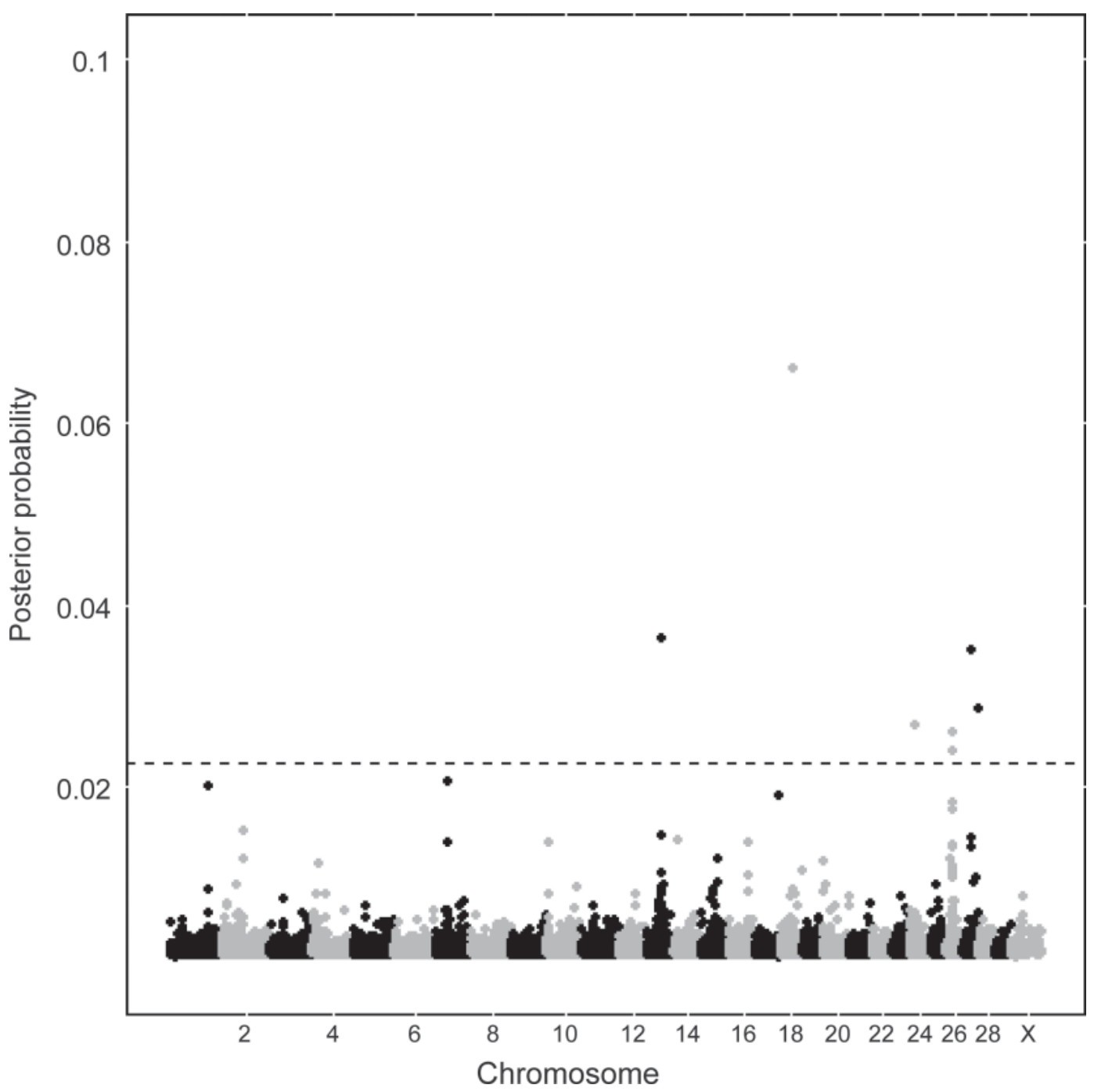

Figure 2. Posterior QTL probabilities for cumulated predicted enteric methane emission from wk 1 to 30 . The dashed horizontal line is the threshold associated with a Bayes factor of 10.1. 
of selection, as more young stock will be required to maintain the herd size, because more dairy cows may be culled involuntarily and need to be replaced with young stock that are also producing methane.

In addition, in a practical breeding program, more traits will be considered in the breeding goal; for example, milk production, fertility, or longevity. Although simultaneous selection for other traits will reduce the selection pressure on methane emission per se, these traits might help to achieve even more progress than is achieved by selecting for methane alone (Jones et al., 2008; Bell et al., 2011). For example, Bell et al. (2010) already demonstrated savings of 19 and $23 \%$ in enteric methane per kilogram of milk when cows were selected for milk fat plus protein solely, or selected to remain close to the average genetic merit for milk fat plus protein production, respectively. Yan et al. (2010) concluded that selection of dairy cows capable of high levels of milk production and energy utilization efficiency offers an effective approach to reducing $\mathrm{CH}_{4}$ emissions from lactating dairy cows. More extensive life cycle assessment of methane mitigation might help to translate the effects of selection at individual animal level to effects at farm or higher system level (de Vries and De Boer, 2010; Del Prado et al., 2010).

Recording Methane. The greatest limitation to achieving these theoretical targets is the recording of methane emissions at the individual cow level or, as in this study, recording feed intake to calculate PME. Currently, this is too complicated and too expensive in a progeny-testing scheme, and therefore alternatives need to be developed. Selection on milk production gave a good response (Bell et al., 2010) but ignored genetic variation between animals in feed efficiency, other than dividing the energy needed for maintenance over more kilograms of milk. Alternative phenotype measures under development use sulfur hexafluoride $\left(\mathrm{SF}_{6}\right)$ methodology (Clark et al., 2011), mid-infrared spectral data (Mc Parland et al., 2010), or the "lasergun" methodology (Chagunda et al., 2009b). Still, these methods are in early development or have inherent drawbacks (Clark et al., 2011) in which within-animal variability is of particular concern. For example, the high within-animal variability in $\mathrm{CH}_{4}$ emissions measured using the $\mathrm{SF}_{6}$ technique may result in absence of consistent rankings of individual animals for $\mathrm{CH}_{4}$ yield when measured on multiple occasions and may exaggerate apparent animal differences in methane emissions (Vlaming et al., 2008).

Realistic Breeding Program. The gain in a breeding program is affected by the accuracy of selection (which, in turn, is affected by the number of records), the intensity of selection, and the generation interval, and these might differ for different selection paths (sires to breed sires, sires to breed cows, dams to breed sires, and dams to breed dams). In addition, optimizing the design of a reference population in terms of the genetic relationships between the animals (Pszczola et al., 2011) might help to maximize the benefit of invested costs for measuring direct $\mathrm{CH}_{4}$ or related traits. The predictions discussed are based on a genetic progress of 0.22 genetic SD per year in a typical classic breeding program for dairy cattle. Given the recording limitations that currently exist, it is unlikely that breeding values will have as high accuracy as those achieved for milk yield. However, higher gains might be expected with the use of genomic selection, because the generation interval to breed sires can be reduced considerably. Assuming a generation interval for this selection path of $2 \mathrm{yr}$, and considering an accuracy of 0.37 for breeding values obtained with the SNP key (Table 7), then genetic gain of 0.25 genetic SD per year is expected, which is still higher than the 0.22 assumed for a classical breeding program. For a reference population of 3,000 to 4,000 animals (instead of the 600 used here), the accuracy of the SNP key is predicted to be 0.7, and genetic gain is expected to be 0.47 genetic SD per year (M. P. L. Calus, unpublished data). This would double the genetic gain calculated above, which is in line with theoretical predictions for a genomic selection breeding program (Pryce et al., 2010).

These genetic gains might appear excessive, but Bell et al. (2010) demonstrated reductions in the order of $20 \%$ in enteric methane per kilogram of milk in about $10 \mathrm{yr}$ of selection for milk fat plus protein yield. Without accounting for PME explicitly, Alford et al. (2006) predicted, for a beef cattle program, that selection using RFI would reduce methane production by $16 \%$ in $25 \mathrm{yr}$. This is considerably lower than predicted here. However, their lower response can be explained by the fact that they assumed a beef breeding program with selection on RFI in the males only, whereas we assumed a dairy breeding program, with all 4 selection paths included (i.e., for sires for sires, sires for dams, dams for sires, and dams for dams). Besides, Alford et al. (2006) assumed that half of the selection pressure was on traits other than RFI compared with full selection on PME in the current study.

Obtaining data sets with thousands of animals might be achievable in an international effort bringing data together, as has been done in the RobustMilk project (www.RobustMilk.eu) using data from research herds in different countries. However, these data need to be updated regularly to maintain a close relation between the SNP key and PME in the population.

\section{CONCLUSIONS}

Large variation exists in DMI and predicted enteric $\mathrm{CH}_{4}$ emission among first-lactation cows, expressed 
both as PME per day and as PME per kilogram of FPCM, despite the fact that the animals received a similar diet. A large part of the variation was genetic (heritability of 0.35 for PME and of 0.58 for PME per FPCM) and significant effects of individual SNP were identified. Classic selection programs could reduce predicted methane emission by 11 and $26 \%$ in $10 \mathrm{yr}$ when expressed as kilograms per lactation and grams per kilograms of FPCM, respectively, but it is unknown if this selection would also result in actual (measured) methane emissions. The greatest limitation for a breeding scheme is in measuring feed intake (or methane emission) on progeny of sires. Genomic selection based on a reference population established through an international effort combining data might provide a solution.

\section{ACKNOWLEDGMENTS}

The authors acknowledge funding for the study from the Dutch Dairy Board (PZ; Zoetermeer, the Netherlands) and AgentschapNL (The Hague, the Netherlands). The study was also performed as part of the RobustMilk project. The RobustMilk project is financially supported by the European Commission under the Seventh Research Framework Programme, Grant Agreement KBBE-211708. This publication represents the views of the authors, not the European Commission, and the Commission is not liable for any use that may be made of the information.

\section{REFERENCES}

Alford, A. R., R. S. Hegarty, P. F. Parnell, O. J. Cacho, R. M. Herd, and G. R. Griffith. 2006. The impact of breeding to reduce residual feed intake on enteric methane emissions from the Australian beef industry. Aust. J. Exp. Agric. 46:813-820.

Bannink, A., J. France, S. Lopez, W. J. J. Gerrits, E. Kebreab, S. Tamminga, and J. Dijkstra. 2008. Modelling the implications of feeding strategy on rumen fermentation and functioning of the rumen wall. Anim. Feed Sci. Technol. 143:3-26.

Bannink, A., M. W. Van Schijndel, and J. Dijkstra. 2011. A model of enteric fermentation in dairy cows to estimate methane emission for the Dutch National Inventory Report using the IPCC Tier 3 approach. Anim. Feed Sci. Technol. 166-167:603-618.

Beauchemin, K. A., M. Kreuzer, F. O'Mara, and T. A. McAllister. 2008. Nutritional management for enteric methane abatement: A review. Aust. J. Exp. Agric. 48:21-27.

Bell, M. J., E. Wall, G. Russell, C. Morgan, and G. Simm. 2010. Effect of breeding for milk yield, diet and management on enteric methane emissions from dairy cows. Anim. Prod. Sci. 50:817-826.

Bell, M. J., E. Wall, G. Russell, G. Simm, and A. W. Stott. 2011. The effect of improving cow productivity, fertility, and longevity on the global warming potential of dairy systems. J. Dairy Sci. 94:3662-3678

Calus, M. P. L., T. H. E. Meuwissen, A. P. W. De Roos, and R. F. Veerkamp. 2008. Accuracy of genomic selection using different methods to define haplotypes. Genetics 178:553-561.

Cavanagh, A., L. McNaughton, H. Clark, C. Greaves, J. M. Gowan, C. Pinares-Patino, D. Dalley, B. Vlaming, and G. Molano. 2008. Methane emissions from grazing Jersey $\times$ Friesian dairy cows in mid lactation. Aust. J. Exp. Agric. 48:230-233.
Chagunda, M. G. G., D. A. M. Romer, and D. J. Roberts. 2009a. Effect of genotype and feeding regime on enteric methane, non-milk nitrogen and performance of dairy cows during the winter feeding period. Livest. Sci. 122:323-332.

Chagunda, M. G. G., D. Ross, and D. J. Roberts. 2009b. On the use of a laser methane detector in dairy cows. Comput. Electron. Agric. 68:157-160.

Clark, H., F. Kelliher, and C. Pinares-Patino. 2011. Reducing CH4 emissions from grazing ruminants in New Zealand: Challenges and opportunities. Asian-australas. J. Anim. Sci. 24:295-302.

de Vries, M., and I. J. M. De Boer. 2010. Comparing environmental impacts for livestock products: A review of life cycle assessments. Livest. Sci. 128:1-11.

de Vries, M. J., and R. F. Veerkamp. 2000. Energy balance of dairy cattle in relation to milk production variables and fertility. J. Dairy Sci. 83:62-69.

Del Prado, A., D. Chadwick, L. Cardenas, T. Misselbrook, D. Scholefield, and P. Merino. 2010. Exploring systems responses to mitigation of GHG in UK dairy farms. Agric. Ecosyst. Environ. 136:318-332.

Durunna, O. N., F. D. N. Mujibi, L. Goonewardene, E. K. Okine, J. A. Basarab, Z. Wang, and S. S. Moore. 2011. Feed efficiency differences and reranking in beef steers fed grower and finisher diets. J. Anim. Sci. 89:158-167.

Ellis, J. L., A. Bannink, J. France, E. Kebreab, and J. Dijkstra. 2010. Evaluation of enteric methane prediction equations for dairy cows used in whole farm models. Glob. Change Biol. 16:3246-3256.

Ellis, J. L., E. Kebreab, N. E. Odongo, B. W. McBride, E. K. Okine, and J. France. 2007. Prediction of methane production from dairy and beef cattle. J. Dairy Sci. 90:3456-3466.

Friggens, N. C., P. Berg, P. Theilgaard, I. R. Korsgaard, K. L. Ingvartsen, P. Lovendahl, and J. Jensen. 2007. Breed and parity effects on energy balance profiles through lactation: Evidence of genetically driven body energy change. J. Dairy Sci. 90:5291-5305.

Friggens, N. C., and J. R. Newbold. 2007. Towards a biological basis for predicting nutrient partitioning: The dairy cow as an example. Animal 1:87-97.

Gelman, A., and D. B. Rubin. 1992. Inference from iterative simulation using multiple sequences. Stat. Sci. 7:457-472.

George, E. I., and R. E. McCulloch. 1993. Variable selection via Gibbs sampling. J. Am. Stat. Assoc. 88:881-889.

Gilmour, A. R., B. J. Gogel, B. R. Cullis, and R. Thompson. 2006. ASReml User Guide Release 2.0. VSN International Ltd., Hemel Hempstead, UK.

Guan, L. L., J. D. Nkrumah, J. A. Basarab, and S. S. Moore. 2008. Linkage of microbial ecology to phenotype: Correlation of rumen microbial ecology to cattle's feed efficiency. FEMS Microbiol. Lett. 288:85-91.

Hegarty, R. S., J. P. Goopy, R. M. Herd, and B. McCorkell. 2007. Cattle selected for lower residual feed intake have reduced daily methane production. J. Anim. Sci. 85:1479-1486.

Herd, R. M., P. F. Arthur, R. S. Hegarty, and J. A. Archer. 2002. Potential to reduce greenhouse gas emissions from beef production by selection for reduced residual feed intake. Proc. 7th World Congr. Genet. Appl. Livest. Prod., Montpellier, France. Comm. No. 10-22.

IPCC. 2000. Good practice guidance and uncertainty management in national greenhouse gas inventories. L. G. M. F. J. T. Houghton, B. Lim, K. Treanton, I. Mamaty, Y. Bonduki, D. J. Griggs, and B. A. Callanders, ed. OECD, Paris, France. Accessed Sep. 27, 2011. http://www.ipcc-nggip.iges.or.jp/public/gp/english/.

IPCC. 2006. 2006 IPCC guidelines for national greenhouse gas inventories, Vol. 4: Agriculture, Forestry and Other Land Use, Intergovernmental Panel on Climate Change. Accessed Sep. 27, 2011. http://www.ipcc-nggip.iges.or.jp/public/2006gl/pdf/4_Volume4/ V4_10_Ch10_Livestock.pdf.

Jones, H. E., C. C. Warkup, A. Williams, and E. Audsley. 2008. The effect of genetic improvement on emission from livestock systems. Page 28 in Proc. Eur. Assoc. Anim. Prod., Vilnius, Lithuania.

Mc Parland, S., G. Banos, E. Wall, M. P. Coffey, H. Soyeurt, R. F. Veerkamp, and D. P. Berry. 2010. Predicting energy balance status of Holstein cows using mid-infrared spectral data. Proc. 9th World 
Congr. Genet. Appl. Livest. Prod., Leipzig, Germany. Comm. No. 05-70

McAllister, T. A., and C. J. Newbold. 2008. Redirecting rumen fermentation to reduce methanogenesis. Aust. J. Exp. Agric. 48:7-13.

McAllister, T. A., E. K. Okine, G. W. Mathison, and K. J. Cheng. 1996. Dietary, environmental and microbiological aspects of methane production in ruminants. Can. J. Anim. Sci. 76:231-243.

Meuwissen, T. H., B. Hayes, and M. Goddard. 2001. Prediction of total genetic value using genome-wide dense marker maps. Genetics 157:1819-1829.

Meuwissen, T. H. E., and M. E. Goddard. 2004. Mapping multiple QTL using linkage disequilibrium and linkage analysis information and multitrait data. Genet. Sel. Evol. 36:261-279.

Moss, A. R., J. P. Jouany, and J. Newbold. 2000. Methane production by ruminants: Its contribution to global warming. Ann. Zoot. $49: 231-253$.

Murray, R. M., A. M. Bryant, and R. A. Leng. 1976. Rates of production of methane in rumen and large-intestine of sheep. Br. J. Nutr. 36:1-14.

Nkrumah, J. D. E. K. Okine, G. W. Mathison, K. Schmid, C. Li, J. A. Basarab, M. A. Price, Z. Wang, and S. S. Moore. 2006. Relationships of feedlot feed efficiency, performance, and feeding behavior with metabolic rate, methane production, and energy partitioning in beef cattle. J. Anim. Sci. 84:145-153.

Pryce, J. E., M. E. Goddard, H. W. Raadsma, and B. J. Hayes. 2010 Deterministic models of breeding scheme designs that incorporate genomic selection. J. Dairy Sci. 93:5455-5466.

Pszczola, M., T. Strabel, H. A. Mulder, and M. P. L. Calus. 2011. Reliability of genomic values for animals with different relationships within and to the reference population. J. Dairy Sci. doi:10.3168/ jds.2011-4338.

Rendel, J. M., and A. Robertson. 1950. The use of progeny testing with artificial insemination in dairy cattle. J. Genet. 50:21-31.

Van Es, A. J. H. 1978. Feed evaluation for ruminants. 1. Systems in use from May 1977 onwards in Netherlands. Livest. Prod. Sci. $5: 331-345$.

van Knegsel, A. T. M., H. Van den Brand, J. Dijkstra, and B. Kemp. 2007. Effects of dietary energy source on energy balance, metabolites and reproduction variables in dairy cows in early lactation. Theriogenology 68:S274-S280.
Veerkamp, R. F. 1998. Selection for economic efficiency of dairy cattle using information on live weight and feed intake: A review. J. Dairy Sci. 81:1109-1119.

Veerkamp, R. F. 2002. Feed intake and energy balance in lactating animals. Proc. 7th World Congr. Genet. Appl. Livest. Prod., Montpellier, France. Comm. No. 10-01

Veerkamp, R. F., B. Beerda, and T. Van der Lende. 2003. Effects of genetic selection for milk yield on energy balance, levels of hormones, and metabolites in lactating cattle, and possible links to reduced fertility. Livest. Prod. Sci. 83:257-275.

Veerkamp, R. F., and G. C. Emmans. 1995. Sources of genetic variation in energetic efficiency of dairy cows. Livest. Prod. Sci. 44:87-97.

Veerkamp, R. F., J. K. Oldenbroek, H. J. Van Der Gaast, and J. H. J. Van Der Werf. 2000. Genetic correlation between days until start of luteal activity and milk yield, energy balance, and live weights. J. Dairy Sci. 83:577-583.

Verbyla, K. L., M. P. L. Calus, H. A. Mulder, Y. de Haas, and R. F. Veerkamp. 2010. Predicting energy balance for dairy cows using high-density single nucleotide polymorphism information. J. Dairy Sci. 93:2757-2764.

Vlaming, J. B., N. Lopez-Villalobos, I. M. Brookes, S. O. Hoskin, and H. Clark. 2008. Within-and between-animal variance in methane emissions in non-lactating dairy cows. Aust. J. Exp. Agric. 48:124-127.

Wall, E., G. Simm, and D. Moran. 2010. Developing breeding schemes to assist mitigation of greenhouse gas emissions. Animal 4:366376.

Wiggans, G. R., T. S. Sonstegard, P. M. Vanraden, L. K. Matukumalli, R. D. Schnabel, J. F. Taylor, F. S. Schenkel, and C. P. Van Tassell. 2009. Selection of single-nucleotide polymorphisms and quality of genotypes used in genomic evaluation of dairy cattle in the United States and Canada. J. Dairy Sci. 92:3431-3436.

Yan, T., C. S. Mayne, F. G. Gordon, M. G. Porter, R. E. Agnew, D. C. Patterson, C. P. Ferris, and D. J. Kilpatrick. 2010. Mitigation of enteric methane emissions through improving efficiency of energy utilization and productivity in lactating dairy cows. J. Dairy Sci. 93:2630-2638. 